\title{
Experimental study on mitigation of liquefaction-induced vertical ground displacement by using gravel and geosynthetics
}

Hendra Setiawan ${ }^{1,2^{*}}$ D, Yuko Serikawa ${ }^{1}$, Wataru Sugita ${ }^{1}$, Hajime Kawasaki ${ }^{3}$ and Masakatsu Miyajima ${ }^{1}$

\begin{abstract}
Background: Earthquakes in liquefaction-prone areas are frequently followed by the settlement of surface structures due to subsoil liquefaction. This paper aims to study the influence of geosynthetics along with gravel usage to reduce the vertical soil displacement caused by liquefaction using a shake table equipment. This influence is analyzed by means of measuring soil acceleration, pore water pressures and vertical soil deformation due to the shaking process.
\end{abstract}

Results: Results of a series of 1-g shaking table tests which have been conducted in different initial relative densities which are 50\% (loose sand conditions) and 90\% (dense sand conditions) to evaluate the performance of proposed mitigation against settlement problem are presented. It is found that ground settlement reduced around $11.4 \mathrm{~mm}$ for loose sand conditions, from $20.9 \mathrm{~mm}$ in the case with no countermeasure (Case 1) to $9.5 \mathrm{~mm}$ in the Case reinforced with gravel and geosynthetics Type II (Case 4). Correspondingly, for dense sand states, the settlement decreased by about $1.8 \mathrm{~mm}$, from $5.6 \mathrm{~mm}$ in the Case 1 to $3.8 \mathrm{~mm}$ in Case 4. Moreover, a differential settlement between loose sand and dense sand conditions decreased as well, around $9.6 \mathrm{~mm}$, from $15.3 \mathrm{~mm}$ in the Case 1 to $5.7 \mathrm{~mm}$ in Case 4.

Conclusions: By conducted a series of shake table tests, it is confirmed that the vertical ground displacement decreased by the use of geosynthetics and gravel up to $54 \%$ and $32 \%$ for loose sand and dense sand states, respectively. Furthermore, test results also show that there is a decrease in the differential settlement between loose sand and dense sand conditions, around $62 \%$.

Keywords: Liquefaction, Vertical displacement, Differential settlement, Relative density, Gravel, Geosynthetics, Shaking table test

\section{Background}

Liquefaction is one of the phenomena which occur in the saturated loose sand layer during an earthquake. It takes place when the pore water pressure reaches a particular value which is close to the total stress of soil. One of the consequences that can occur is structures built on top or within the liquefied ground may fail due to ground settlement.

\footnotetext{
* Correspondence: hendra3909@gmail.com

'Kanazawa University, Kakuma-Machi, Kanazawa-Shi, Ishikawa Prefecture 920 1192, Japan

${ }^{2}$ Tadulako University, Bumi Tadulako Tondo Campus, Palu, Central Sulawesi

94118, Indonesia

Full list of author information is available at the end of the article
}

Landfilled ground occasionally liquefies due to a large-scale earthquake and triggers deformations on the ground surface and undermine construction lying on it, for example, the roads (Takahashi et al. 2015). This phenomenon occurred because the liquefied layer is having low strength when shocked with large amplitude seismic waves, caused large movements to the road surface, and as a result, deformation of the road surface took place. Nevertheless, even though the road surface was composed of asphalt and roadbed and had high-strength if the ground under the road surface is liquefied, the deformation will occur. 
Furthermore, the extent of the ground deformation is influenced by several factors, one of which is the relative density $(D r)$ of the ground. When earthquake-induced liquefaction occurs in the areas with different density, ground differential settlement can take place and may cause damage to a construction built on it, such as the building tilted and roads become uneven/bumpy. Moreover, in the severe condition and significant differential settlement appears, this can lead to, for example, impassable roads. However, for the important roads, such as main roads, emergency evacuation routes, and roads connected to essential facilities, it is necessary to ensure the accessibility of these valuable roads during earthquakes. For that reason, it is necessary to restrain liquefaction-induced ground displacement by an economical and simple to be implemented method. Figure 1a shows the damaged road of the Joban Motorway near Mito, Ibaraki, due to liquefaction in the Great East Japan Earthquake (Anon 2011); Fig. 1b presents the damaged road caused by liquefaction in the Great Hanshin Earthquake, Kobe, Japan (Anon 1995); Fig. 1c displays the tilted residential house due to liquefaction in the 2016 Kumamoto Earthquake, Japan.

Many types of research have been carried out to investigate the ground displacement due to liquefaction phenomenon. For example, Ueng et al. (2010) presented that significant volume changes occur only when there is liquefaction of sand. Otherwise, the settlement is tiny. Among the variety of liquefaction countermeasure methods proposed, the use of gravel, geosynthetics, or geosynthetics in conjunction with gravel attracted some attention due to their effectiveness and relatively low cost. This method is thought to be a good technique to mitigate liquefiable soil problems. For instance, as presented by Murakami et al. (2010), a combination of geosynthetics and gravel to restrain liquefaction in embankments, focused on the vertical displacement of the embankments. The result showed that the settlement of the embankments decreased by nearly $35 \%$ by using gravel and geosynthetics. They concluded that the use of geosynthetics sandwiched between gravel would have high resistance to bending deformation due to the overburden load of the embankment. Even though this method does not overcome the occurrence of liquefaction completely, it does alleviate the excessive deformation such as settlement and lateral movement. Correspondingly, Noorzad and Amini (2014) pointed out that the fiber attachments considerably enhanced liquefaction resistance of sand specimens. Upon raising the fiber content and fiber length, the number of loading cycles leading to liquefaction enlarged.

Harmoniously, some other research also showed corresponding results, for example by use gravel presented by Orense et al. (2003), Morikawa et al. (2014), and Chang et al. (2014), and geosynthetics utilized reported by Vercuil et al. (1997), and Boominathan and Hari (2002).

Research related to the use of gravel combined with geosynthetics in order to mitigate ground deformation triggered by liquefaction is poorly investigated. This proposed mitigation method is expected to be widely used to overcome ground settlement due to liquefaction since it has the following advantages; 1) more economical compared to other methods such as vibration or sand piling. According to the Japanese Geotechnical Society (JGS) Kanto branch, ground reinforcement by using the banded geosynthetics type Paralink $300 \mathrm{~L}$, the cost is around $1250 \mathrm{JPY}$ (12 USD)/ $\mathrm{m}^{2}$, whereas by using static

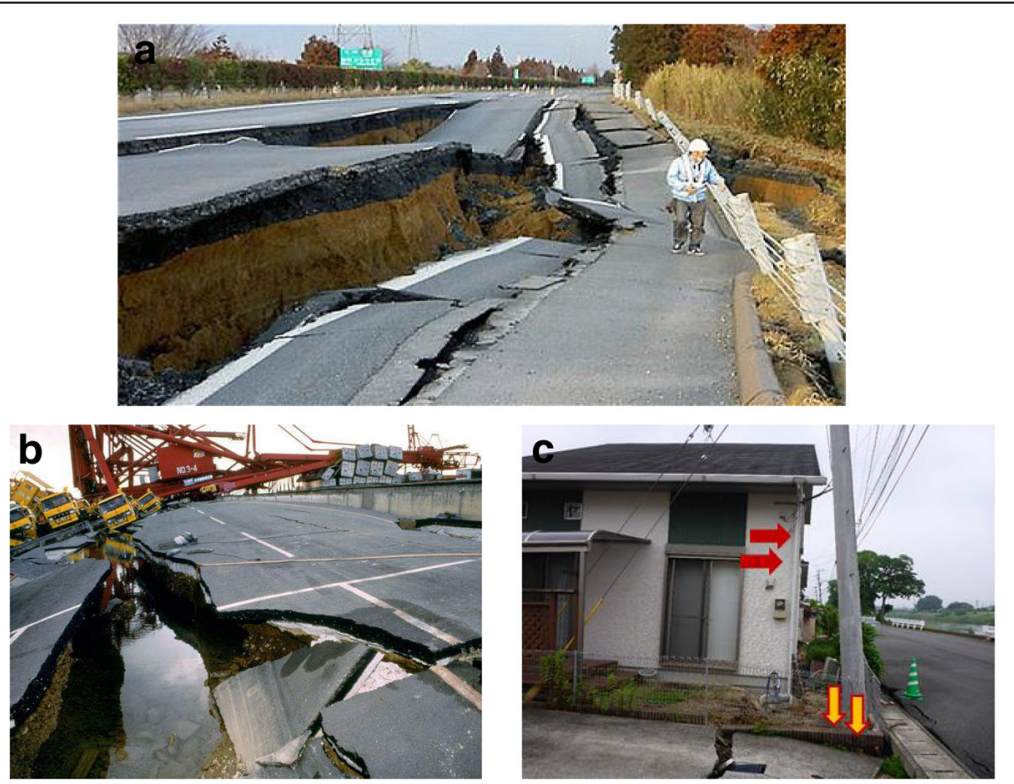

Fig. 1 a Damaged road due to liquefaction in the Great East Japan earthquake. b Damaged road due to liquefaction in the Great Hanshin earthquake, Japan. c Tilted house due to liquefaction in the 2016 Kumamoto earthquake, Japan 
Table 1 Index properties of the materials used

\begin{tabular}{lllll}
\hline Index Properties & Silica sand No. 7 & Crushed stone No. 5 & Geosynthetic Type I & Geosynthetic Type II \\
\hline Density, $\rho, \mathrm{g} / \mathrm{cm}^{3}$ & 2.66 & 2.56 & - & - \\
Mean grain size, $D_{50}, \mathrm{~mm}$ & 0.17 & 3.55 & - & - \\
Relative density, Dr, \% & $50 \& 90$ & - & - & - \\
Tensile strength, $T, \mathrm{kN} / \mathrm{m}$ & - & - & 6.37 & 10.43 \\
Tensile stiffness, $E A, \mathrm{kN} / \mathrm{m}$ & - & - & 63.7 & 233.9 \\
\hline
\end{tabular}

clamping sand piling method about 20,000-30,000 JPY (180-270 USD) $/ \mathrm{m}^{2}$ and by vibration type SCP method approximately $10,000 \mathrm{JPY}$ (90 USD)/m². 2) more workable, due to this method is simpler to be executed. 3) lower impact on the surrounding environment, because of vibration and noise caused by the use of heavy equipment during the installing process is less than other methods. 4) high strength and durability; Geosynthetics are material which provide high tensile strength and high durability due to its resistance to heat, weather, and chemical effects.

This paper highlights on studying the performance of the gravel along with geosynthetics to reduce liquefaction-induced vertical ground displacement by conducting a series of shaking table tests. The effectiveness of the gravel and geosynthetics was evaluated through the settlement occurred at the ground surface.

\section{Methodologies}

\section{Shaking table test}

The sand container used had dimensions of $1500 \mathrm{~mm}$ length, $750 \mathrm{~mm}$ width, and $750 \mathrm{~mm}$ height and built from galvanized steel and acrylic/plexiglass. The sand layer in the sand container was divided into two parts, which are not-liquefiable, composed of dense sand with a relative density $(D r)$ $90 \%$, and liquefiable sand, composed of loose sand with $\mathrm{Dr}$ around $50 \%$. The sand used in this research was silica sand No. 7. The remedial measures utilized in this study were gravel and geosynthetics. Crushed stone No. 5 was used to form a model of a gravel layer of $6 \mathrm{~cm}$ thick. This type of crushed stone is widely used as gravel in modeling tests, for example, used by Takahashi et al. in 2015. Furthermore, a sheet of model geosynthetics made of polyethylene placed at the bottom of the gravel layer. In this study, two different types of geosynthetics (Type I and Type II) were used to know the influence of friction between geosynthetics and sand to ground displacement that appeared. Properties of the materials used (silica sand No. 7, crushed stone No. 5, and geosynthetics) in this series of tests can be seen in Table 1. Specifications of instruments used such as acceleration transducer, water pressure meter, and displacement transducer can be seen in Table 2. The photographs of the model geosynthetics used are shown in Fig. 2.

Input harmonic wave used were as follows: frequency $5 \mathrm{~Hz}$, a target maximum input acceleration of around 80 $\mathrm{cm} / \mathrm{s}^{2}$, and a shaking duration time of $15 \mathrm{~s}$.

In this study, four cases were observed. Firstly, a ground model without countermeasure (Case 1). To determine the effect of the gravel usage, the ground model reinforced with gravel only (Case 3). The effectiveness of gravel and geosynthetics will be verified in Case 3 and Case 4 . In case 3, the ground strengthened with geosynthetics type I below the gravel layer, whereas in Case 4, geosynthetics type II was put below the gravel layer to reinforce the ground. Figure 3 shows the plan view and the cross-section of the unreinforced model (Case 1), reinforced with gravel (Case 2) and gravel accompanied by geosynthetics Type I and II (Cases 3 and 4) along with the layout of accelerometers, water pressure meters, and displacement meters. The ground in the model composed of a liquefiable (loose) sand layer with a relative density around $50 \%$, non-liquefiable part with relative density $90 \%$ in dense condition, and dry sand on the ground surface.

\section{Ground amplification test}

To determine the impact of gravel and geosynthetic usage on ground acceleration, in the loose and dense sand conditions, a series of additional tests were performed. The results of this test will be analyzed and will be determined by changes in the ratio of amplification factors on each test. The ratio of the amplification factor is the ratio between the amplitude acceleration measured at the ground surface divided by the amplitude of the input acceleration on each test performed. In this test, only two cases observed, namely Case

Table 2 Instrument's specifications

\begin{tabular}{llll}
\hline Instruments & Type & Capacities & Company \\
\hline Acceleration transducer & ARF-100A & $100 \mathrm{~cm} / \mathrm{s}^{2}$ & Tokyo Sokki Kenkyujo \\
Water pressure meter & PMS-5-50 K & $-50 \sim+50 \mathrm{kPa}$ & Toyota Kohki \\
Displacement meter & ANR1226 & $150 \mathrm{~mm} / 5.9 \mathrm{in}$ & Matsushita Electric \\
Load cell & CLP-10B & $10 \mathrm{tf}$ & Tokyo Sokki Kenkyujo \\
\hline
\end{tabular}



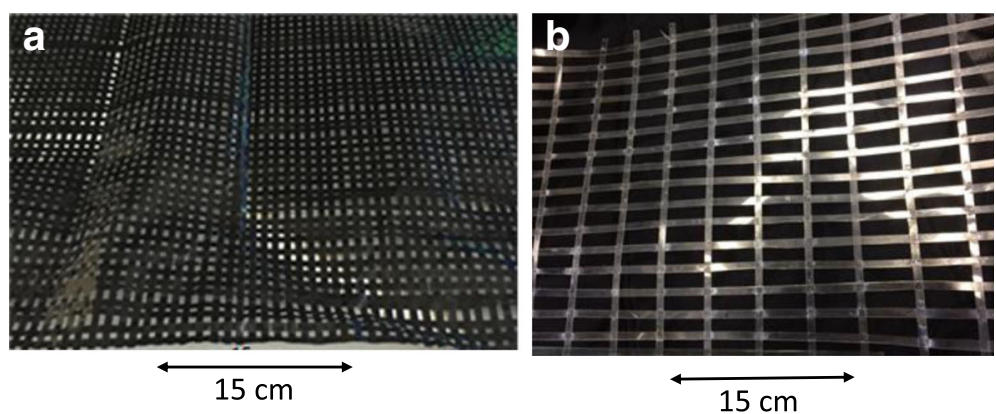

Fig. $\mathbf{2}$ The photograph of the model geosynthetics used. a Geosynthetics type I. b Geosynthetics type II

1 and Case 4. Case 4 was chosen to represent the ground with the reinforced material (Cases 2, 3 and 4). It is thought that these three cases will result in similar results in this ground amplification test.

\section{Pull out test}

In order to determine the interaction between soils and geosynthetics, the experiment described as the pull-out test was conducted as well. This test resulted in friction angle which is an important design parameter for soil structures reinforced with geosynthetics where the friction between the soil and reinforcement elements is mobilized. Figure 4a shows the side view of the pull-out test apparatus. A photograph of the pull-out test instrument can be seen in Fig. 4b.

The test tank used in the pull-out test is built from galvanized steel and acrylic with inner dimensions: $0.8 \mathrm{~m}$ long, $0.6 \mathrm{~m}$ wide and $0.6 \mathrm{~m}$ high. The geosynthetics and sand used are the same as those used in the shake table test. Tensile force, displacements and normal stress were observed.

\section{Results and discussion}

A summary of the data resulted in pull-out test, ground amplification test, and primary data measured during the shaking table test such as excess pore water pressure, acceleration, and settlement of ground surface are presented and discussed.

\section{Pull-out test}

Figure 5 shows the results obtained by pull-out tests for the model of geosynthetics used in this study subjected to various overburden pressures. As shown in this figure, the test using geosynthetics type II provides the higher friction angle, which is around $30.2^{\mathrm{O}}$, compared to geosynthetics type I of only about $23.4^{\mathrm{O}}$. This can be justified due to the thicker and the larger aperture of geosynthetics Type II compared to Type I. This better friction characteristic

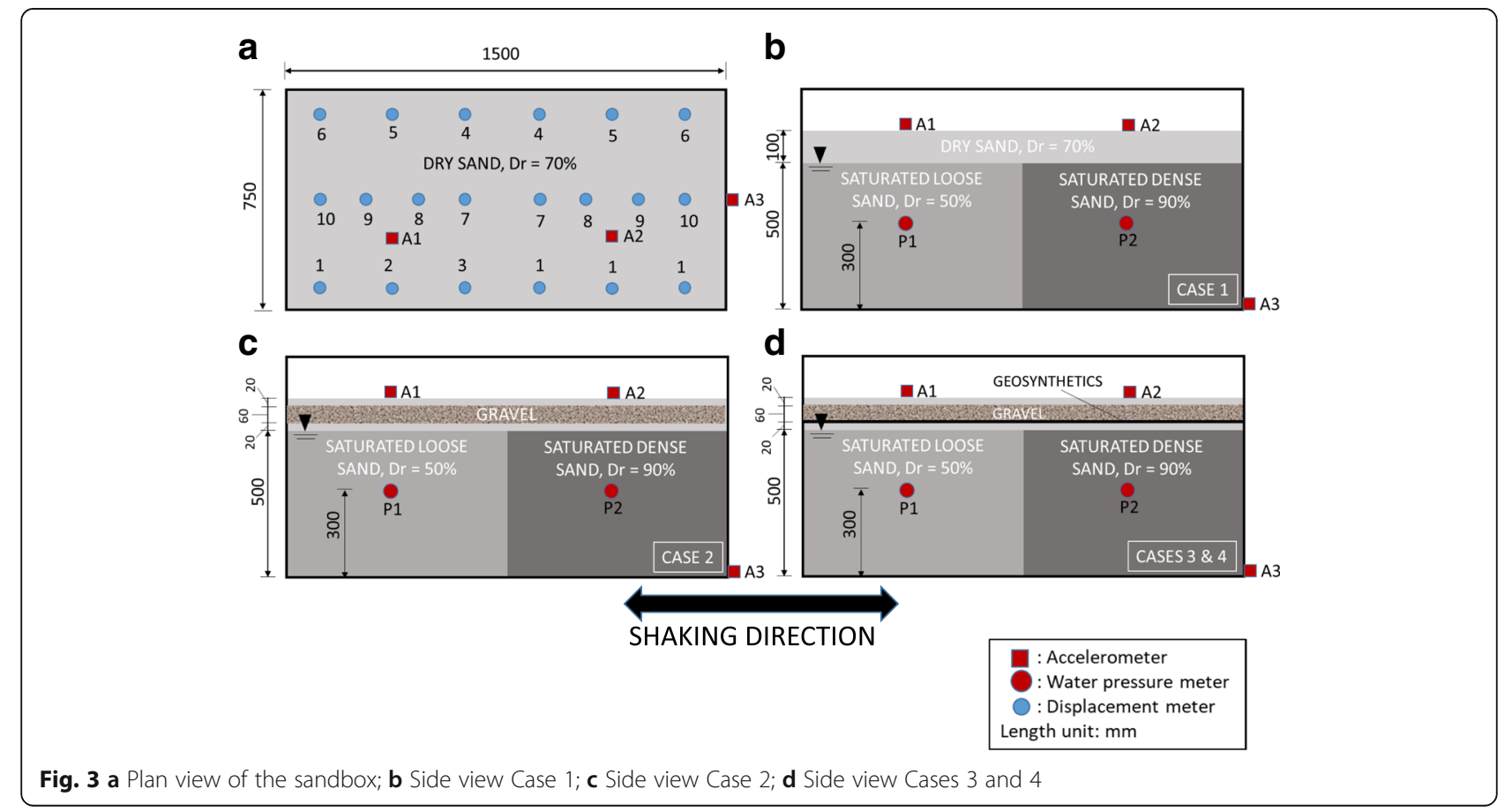




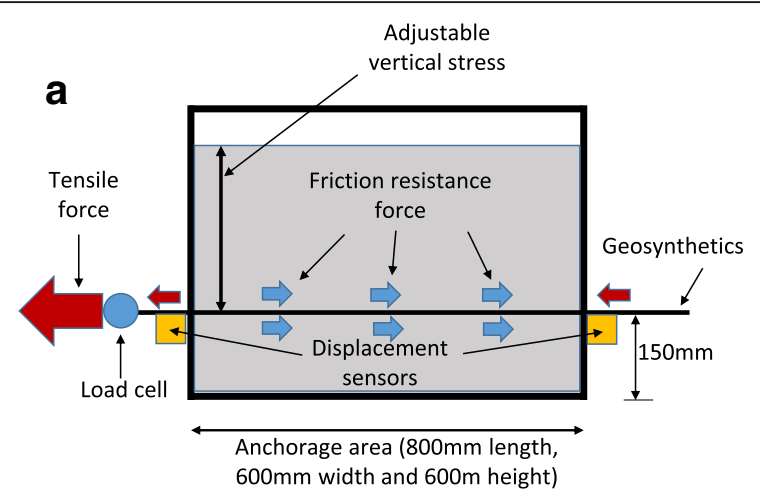

b

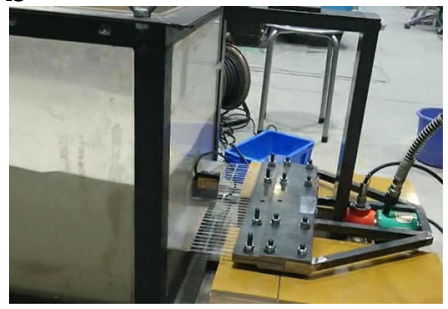

Fig. 4 Pull-out test apparatus. a Side view of the pull-out test apparatus; $\mathbf{b}$ A photograph of the pull-out test apparatus

causing geosynthetics type II more cohesive when blended with other materials, for example, sand and gravel, which is resulted in the increasing of the rigidity of the ground by the presence of the reinforcement layer.

\section{Ground amplification test}

Figure 6 shows the value of the resulting of ground amplification factor ratios. From Fig. 6a it appears that for the loose sand conditions, the maximum amplification ratio decreases by about 29\%, from about 3.1 in Case 1 to 2.2 in Case 4. Similarly, as seen in Fig. 6b, in the case of dense sand conditions, although not as significant as loose sand conditions, also a decrease in maximum amplification factor ratio of about 27\%, from 2.6 in case 1 to 1.9 in case 4. Furthermore, from Fig. $6 \mathrm{a}$ and $\mathrm{b}$ it can also be said that the effect of gravel and geosynthetic to reduce the acceleration amplification was found more significant in dense soil conditions than that of the looser one. In the high-density sand, the maximum amplification factor ratios for case 4 are around 1.9, whereas on the looser sand approximately 2.2. This can be attributed to the more efficient interaction between gravel, geosynthetics, and sand grains at a high density which resulted in the increasing of the rigidity of the ground. It is speculated that the thickness, apertures, the roughness, and tensile strength of the geosynthetics constituted a stronger interlock with the high-density soils than that of looser one due to loose sand corresponds to a higher void ratio.

\section{Shaking table test Pore water pressure}

Pore water pressure was observed by installing two pore water pressure transducers at $30 \mathrm{~cm}$ from the bottom of the sandbox, either for the loose sand or dense sand parts. Excess pore water pressure measured was converted to pore water pressure ratio (PWPR) by dividing excess pore water

\section{Friction angle}

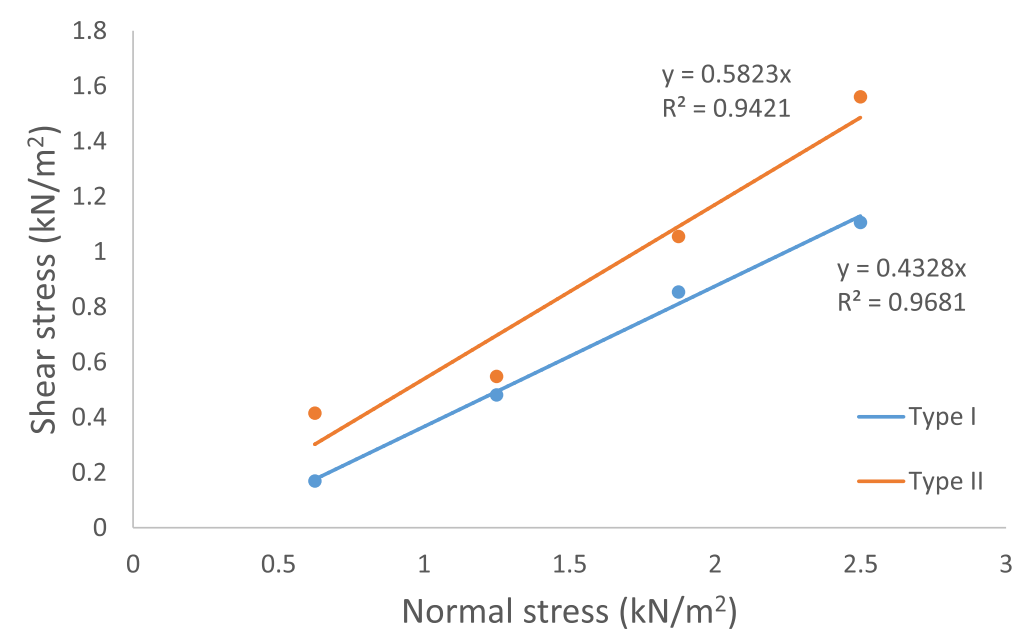

Fig. 5 Friction angle of the geosynthetics resulted from the pull-out test 

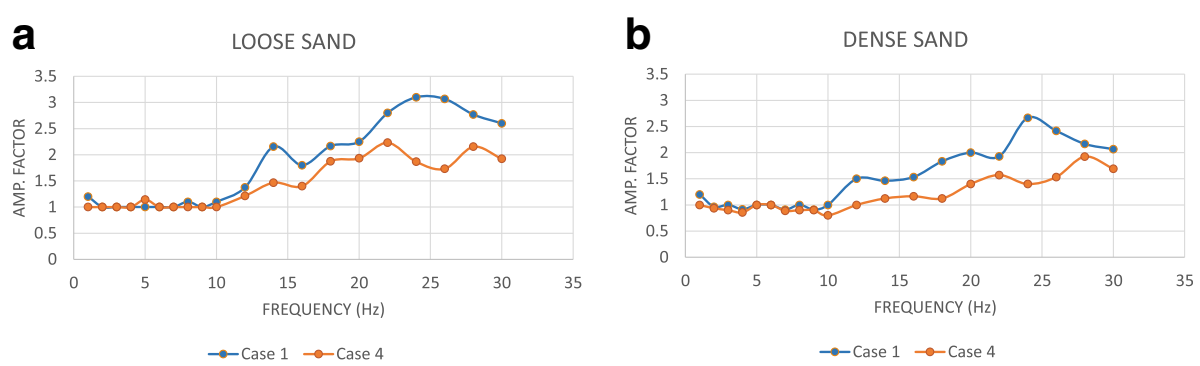

Fig. 6 Amplification factor. a In the loose sand condition; $\mathbf{b}$ In the dense sand condition

pressure with initial vertical effective stress $\left(\sigma_{v}{ }^{\prime}\right)$. Pore water pressure ratio time histories are shown in Fig. 7.

Generally, the results obtained show an insignificant difference in all cases, both for P1 and P2. As can be seen in Fig. 7, for water pressure meter placed in the loose sand zone (P1), although the maximum PWPR obtained is around 1 for Case 2 , but the maximum value in Cases 1 and 3 is also immensely close to 1 , around 0.97 , which indicate that liquefaction occurred. In Case 4, the maximum PWPR is only slightly lower and showed a faster water pressure dissipation, compared to other cases. Correspondingly, for the dense sand state (P2), the maximum PWPR acquired is almost similar for all cases of about 0.4, even though the highest PWPR in Case 4 is little higher compared to other cases. These results signify that no liquefaction occurred in this zone.

According to the results, it can be said that the effect of the use of gravel and geosynthetics on pore water pressure is insignificant in these experiments. Since the main purpose of pore water pressure measurement is to determine the occurrence of liquefaction in the sand layer, therefore the influence of the use of gravel and geosynthetics on pore water pressure is not a major concern.

\section{Acceleration}

Figure 8 shows the acceleration time histories of all cases at the ground surface of the loose sand (A1), the ground surface of the dense sand (A2), and input acceleration (A3). As can be seen from this figure, although the disparity of acceleration is not significant, still can be observed that the presence of gravel and geosynthetics, could decrease the average amplitude of the acceleration obtained. In Case 3, which ground strengthened with gravel and geosynthetics type I, and the ground in the dense state resulted in the lower average amplitude among others. These results are in line with the results acquired in the ground amplification experiments described previously, ground density and the use of reinforcing materials have a positive effect on ground acceleration.

\section{Vertical ground displacement}

The vertical ground displacement occurred through ten different points at the ground surface was measured. To simplify understanding, the displacement values are averaged, and the results can be seen in Fig. 9. It can be observed that based on the averaged vertical ground displacement measured, the presence of the proposed mitigation could reduce vertical displacement in various amounts, for example, by use gravel only (Case 2), in the loose sand condition, the settlement was decreased around $4 \mathrm{~mm}$, from $20.9 \mathrm{~mm}$ to $16.9 \mathrm{~mm}$, and reach approximately $1.9 \mathrm{~mm}$ for the dense condition, from $5.6 \mathrm{~mm}$ to $3.7 \mathrm{~mm}$. Moreover, by applying gravel and geosynthetics type I (Case 3), the displacement was reduced up to $7.6 \mathrm{~mm}$ and $1.7 \mathrm{~mm}$ in the loose sand and dense sand conditions, respectively. Maximum results are shown on reinforcement with gravel and geosynthetics Type II, which the ground settlement lowered around 11.4
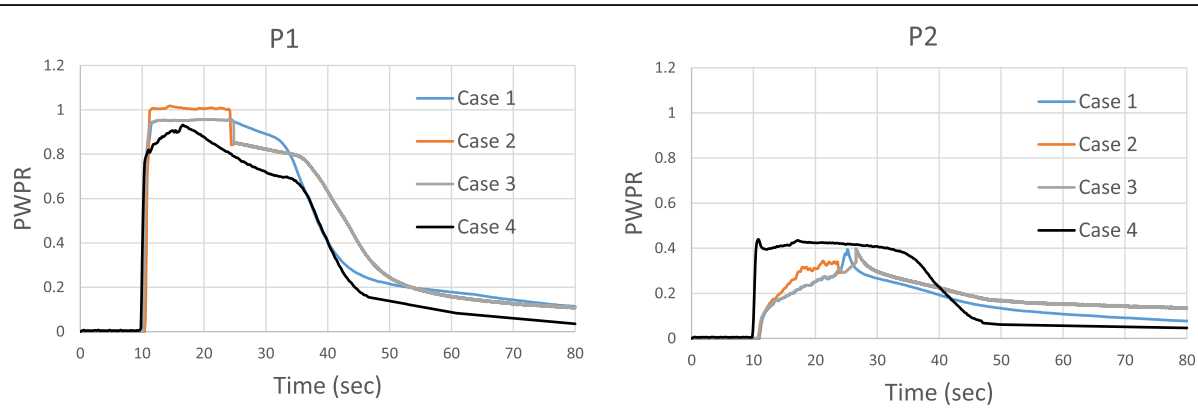

Fig. 7 Pore water pressure ratio time histories 

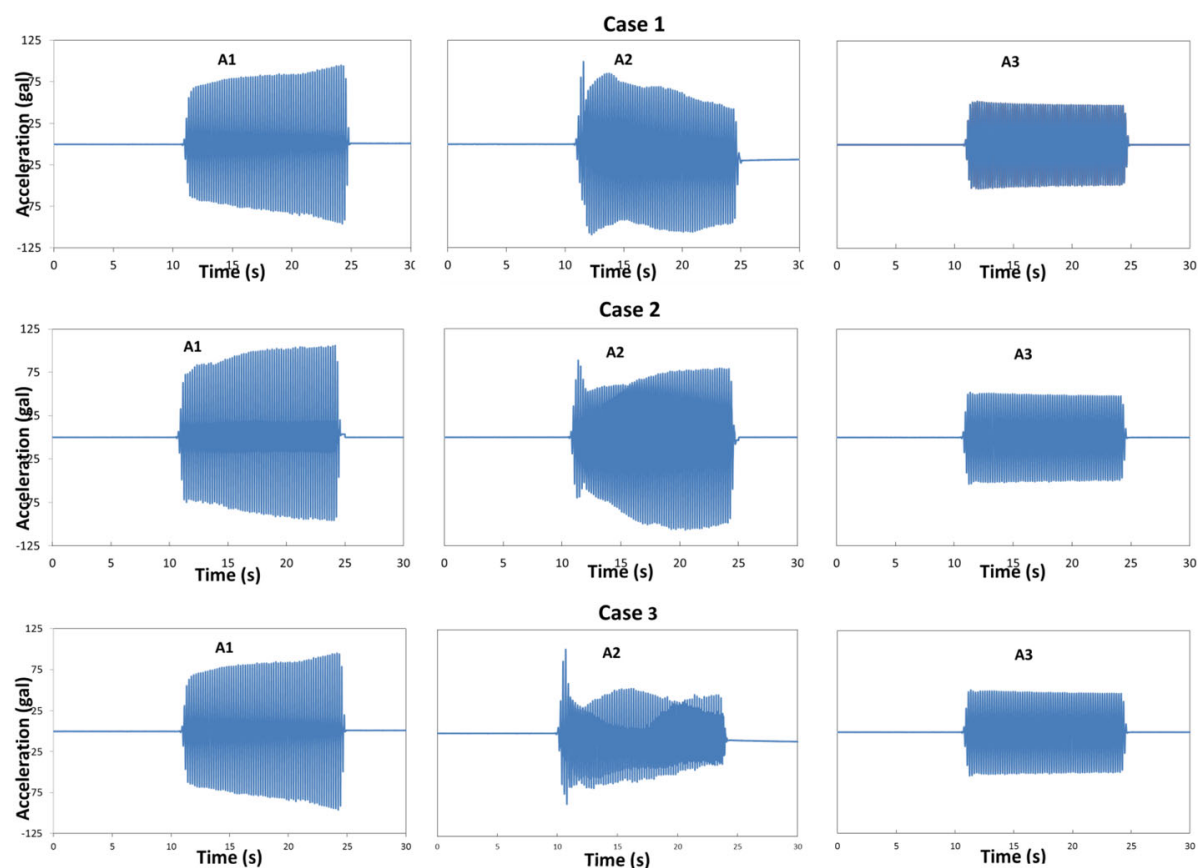

Case 3
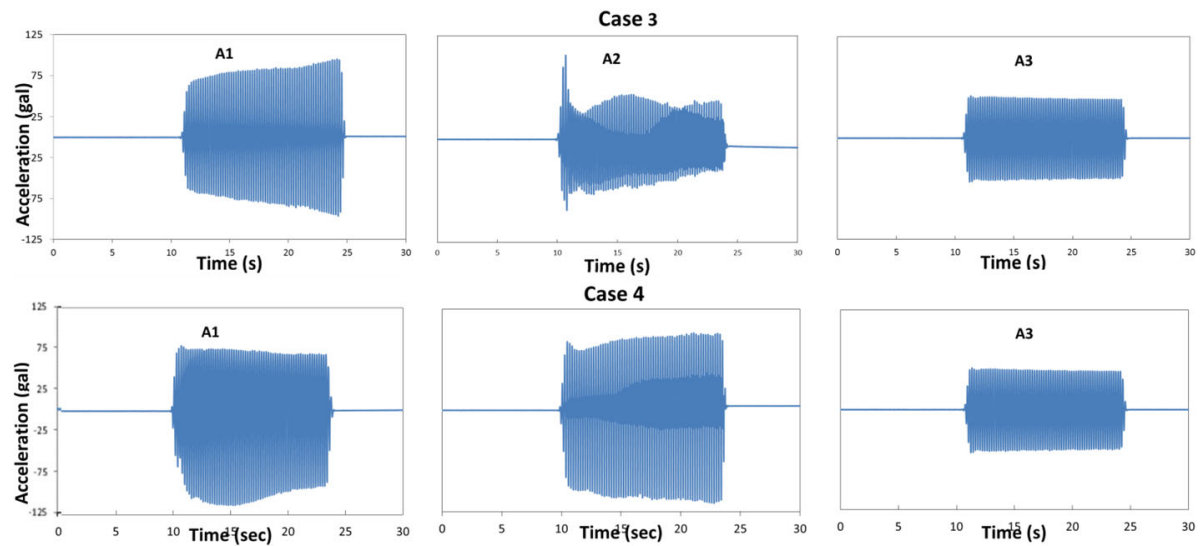

Fig. 8 Acceleration time histories

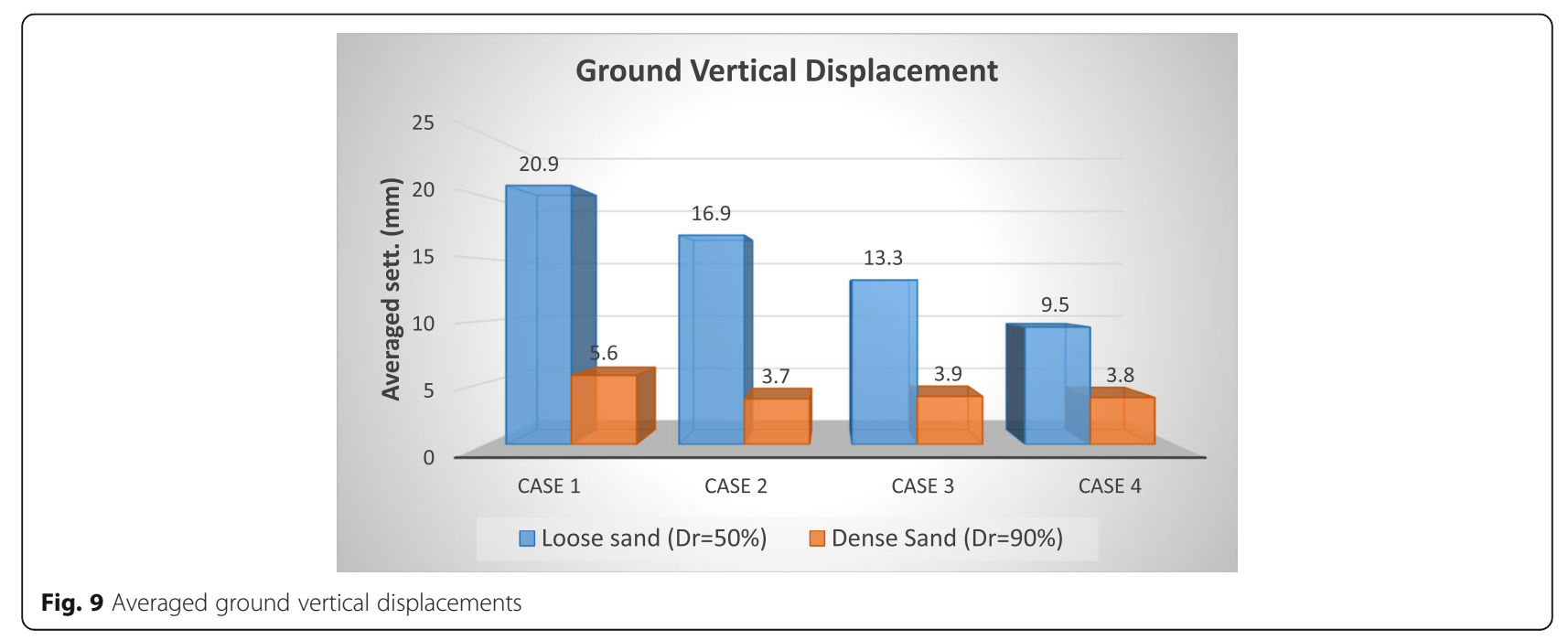




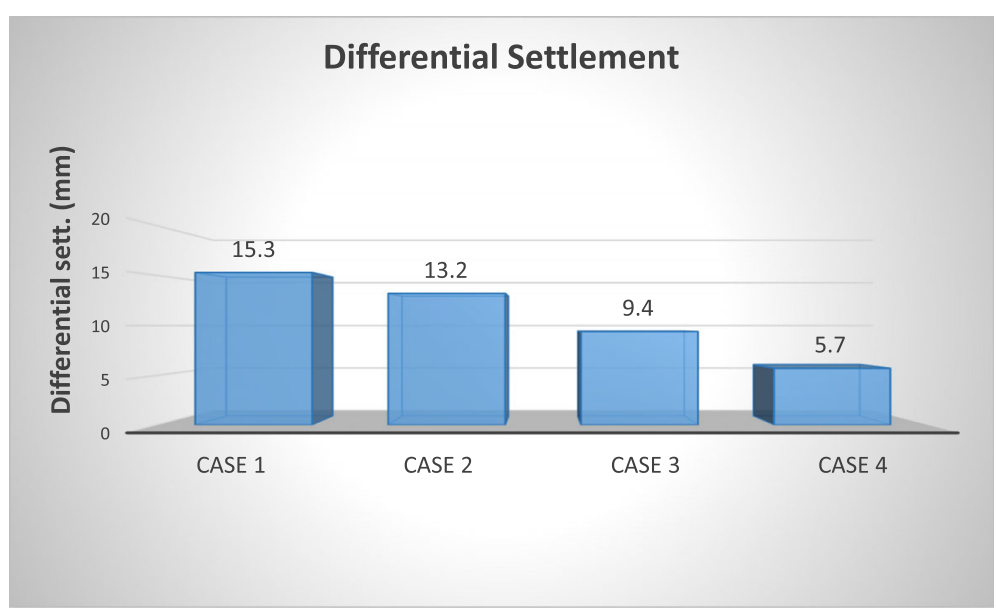

Fig. 10 Differential settlement

$\mathrm{mm}$ in loose sand condition and $1.8 \mathrm{~mm}$ in the dense sand state, compared to Case 1.

Furthermore, the differential settlement between non-liquefiable and liquefiable zones is compared, as shown in Fig. 10. In Case 1, the settlement difference is $15.3 \mathrm{~mm}$, while in Case 2 is $13.2 \mathrm{~mm}$, which means decreased 2.1 $\mathrm{mm}$. The differential settlement is reduced up to $5.9 \mathrm{~mm}$ and $9.6 \mathrm{~mm}$ in Case 3 and Case 4, respectively.

The coherence of the gravel layer with its high permeability and high tensile strength provided by geosynthetics were considered as the main reason for this good result. Since the tension generated in the geosynthetics restrain the deformation of the gravel layer and integrally perform like a rigid plate with high permeability, this reinforcement could reduce the settlement that occurred on the ground surface. Since the tensile strength and the tensile stiffness of geosynthetics Type II that used in Case 4 is higher compared to type I, this type of geosynthetics could restrain the deformation of the gravel and sand better than Type I, resulting in lower ground vertical displacement compared to geosynthetics Type I that used in Case 3.

Based on the results obtained from laboratory testing, this proposed mitigation can be applied to overcome the liquefaction-induced ground settlement and the resulting damage, such as the impassable roads due to differential settlement appeared caused by the subsoil layer liquefy. This will result in substantial losses if this damage occurs on vital roads. Moreover, tilted houses and building also could be appeared due to liquefaction, for instance as happened in Kumamoto earthquake 2016, Japan, where it was reported that many residential houses and buildings were tilted due to liquefaction (Setiawan et al., 2017). The use of gravel and geosynthetics in those examples mentioned above will be able to lower the settlement and the related-damages caused by liquefaction.

\section{Conclusion}

The effectiveness of gravel along with geosynthetics remediation to restrain the liquefaction-induced vertical ground displacement had been measured by conducting a series of shaking table tests. According to the results acquired from the tests carried out, the following conclusions are obtained. It is found that the use of gravel and geosynthetics effectively reduce the vertical ground displacement of liquefiable soil due to the permeability of the gravel and tension strength of the geosynthetics. The conjunction of these two reinforcing materials resulted in a permeable layer which behaves like a rigid plate.

The results showed that by using this proposed mitigation, the settlement of the ground surface decreased by around $54 \%$ in the liquefiable zone and up to $32 \%$ in the non-liquefiable zone. It is also observed that the differential settlement between liquefiable sand and non-liquefiable in the same condition decreased about $62 \%$, from $15.3 \mathrm{~mm}$ in no countermeasure condition to $5.7 \mathrm{~mm}$ when model improved with gravel and geosynthetics Type II. In the future, gravel in conjunction with geosynthetics could be recommended and becomes an established liquefaction countermeasure mitigation due to its aforementioned advantages and effectivity to reduce the liquefaction-induced ground vertical displacement.

\section{Acknowledgments}

Not applicable.

\section{Funding}

The first author obtained a scholarship from The Directorate General of The Ministry of Research, Technology and Higher Education (DG-RTHE) of the Republic of Indonesia as a doctoral student at Kanazawa University, Japan. 


\section{Availability of data and materials}

All data generated or analyzed during this study are included in this published article (and its supplementary information files).

\section{Authors' contributions}

HS, YS, WS, HK, and MM participated in the laboratory shaking table tests. HS and WS prepared the data analysis. HS and MM drafted the manuscript. All authors have read and approved the final manuscript.

\section{Competing interests}

The authors declare that they have no competing interests.

\section{Publisher's Note}

Springer Nature remains neutral with regard to jurisdictional claims in published maps and institutional affiliations.

\section{Author details}

${ }^{1}$ Kanazawa University, Kakuma-Machi, Kanazawa-Shi, Ishikawa Prefecture 920 1192, Japan. ${ }^{2}$ Tadulako University, Bumi Tadulako Tondo Campus, Palu, Central Sulawesi 94118, Indonesia. ${ }^{3}$ Eternal Preserve, Ltd, Ess Building, 3 F, 2-10-10, Yushima, Bunkyo-Ku, Tokyo 113-0034, Japan.

Received: 29 August 2018 Accepted: 26 November 2018

Published online: 04 December 2018

\section{References}

Anon. 1995. Damaged road due to liquefaction in The Great Hanshin Earthquake Japan. Available at: http://1crankyteacher.blogspot.jp/2013/04/kobeearthquake-of-1995.html. Accessed 29 Mar 2018.

Anon. 2011. Damaged road due to liquefaction in The Great East Japan Earthquake. Available at: https://www.telegraph.co.uk/news/worldnews/asia/ japan/8377742/Japan-earthquake-and-tsunami-as-it-happened-March-11.html. Accessed 29 Mar 2018.

Boominathan, A., and S. Hari. 2002. Liquefaction strength of fly ash reinforced with randomly distributed fibers. Journal Soil Dynamics and Earthquake Engineering 22: 1027-1033.

Chang, W.J., C.W. Chang, and J.K. Zheng. 2014. Liquefaction characteristics of gap-graded gravelly soils in $\mathrm{K}_{0}$ condition. Journal Soil Dynamics and Earthquake Engineering 56: 74-85.

Morikawa Y., Maeda K. and Zhang F. (2014) Effectiveness of crushed tile in countermeasure against liquefaction, Journal of GEOMATE, Vol. 7 No. 1 (S1. No. 13), pp. 1003-1008.

Noorzad, R., and P.F. Amini. 2014. Liquefaction resistance of Babolsar sand reinforced with randomly distributed fibers under cyclic loading. Journal Soil Dynamics and Earthquake Engineering 66: 281-292.

Orense, R.P., I. Morimoto, Y. Yamamoto, T. Yumiyama, H. Yamamoto, and K. Sugawara. 2003. Study on wall-type gravel drains as liquefaction countermeasure for underground structures. Journal Soil Dynamics and Earthquake Engineering 23: 19-39.

Setiawan, H., Y. Serikawa, M. Nakamura, M. Miyajima, and M. Yoshida. 2017. Structural damage to houses and buildings induced by liquefaction in the 2016 Kumamoto earthquake, Japan. Journal of Geoenvironmental Disasters 4 (13). https://doi.org/10.1 186/s40677-017-0077-x.

Takahashi, A., S. Seki, A. Pramadiya, Y. Kurachi, H. Aung, and M. Kubo. 2015. Dynamic centrifuge model tests for a liquefaction-induced deformation control method by utilizing geosynthetics, The $50^{\text {th }}$ geotechnical research presentation (Sapporo).

Ueng, T.S., C.W. Wu, H.W. Cheng, and C.H. Chen. 2010. Settlements of saturated clean sand deposits in shaking table tests. Journal Soil Dynamics and Earthquake Engineering 30: 50-60.

Vercuil, D., P. Billet, and D. Cordary. 1997. Study of the liquefaction resistance of saturated sand reinforced with Geosynthetics. Journal Soil Dynamics and Earthquake Engineering 16: 417-425.

\section{Submit your manuscript to a SpringerOpen ${ }^{\circ}$ journal and benefit from:}

- Convenient online submission

- Rigorous peer review

- Open access: articles freely available online

High visibility within the field

- Retaining the copyright to your article

Submit your next manuscript at $\boldsymbol{\nabla}$ springeropen.com 